\title{
Escola como locus da formação continuada e o Pacto Nacional pelo Fortalecimento do Ensino Médio: efeitos na vida dos professores
}

Licinia Maria Correa

Maria Amália de Almeida Cunha

Teodoro Zanardi

Liliane Oliveira Palhares da Silva

\section{Resumo}

O Pacto Nacional pelo Fortalecimento do Ensino Médio (PNEM) é uma política tripartite que uniu esforços da Secretaria de Educação Básica do Ministério da Educação (MEC), das secretarias estaduais de educação e das universidades públicas federais e estaduais. Para analisar os efeitos dessa experiência, tomou-se como universo empírico o processo de formação continuada coordenado e executado pela Universidade Federal de Minas Gerais (UFMG) no biênio 2014-2015. A singularidade dessa formação consistiu em orientar-se para o estudo das Diretrizes Curriculares Nacionais do Ensino Médio, com base em um conjunto de temas que possibilitasse aos docentes refletirem coletivamente sobre o ensino médio enquanto etapa final e essencial da educação básica. A primeira fase da formação teve como temática "Sujeitos do ensino médio e formação humana integral", e a segunda abarcou o exame aprofundado das áreas de conhecimento, contemplando a reescrita coletiva do projeto político-pedagógico da escola. A particularidade e a eficácia desse programa estão na centralidade da escola como locus privilegiado de formação e no professor como sujeito epistêmico que elabora e produz conhecimento.

Palavras-chave: ensino médio; formação de professores; análise da prática pedagógica. 


\section{Abstract \\ The school as locus of continuing education and the Pacto Nacional pelo Fortalecimento do Ensino Médio: effects on teachers' lives}

The Pacto Nacional pelo Fortalecimento do Ensimo Médio (PNEM) is a tripartite policy that united efforts of the Secretaria de Educação Básica do Ministério da Educação (MEC - Ministry of Education's Basic Education Secretariat), states' education secretariats and federal and state public universities. In order to analyze the effects of this experience, the object of the research was the process of continuing education coordinated and executed by the Federal University of Minas Gerais in 2014 and 2015. The singularity of this educational program lies in its orientation to the study of the Diretrizes Curriculares Nacionais do Ensino Médio (National Curricular Guidelines for Secondary School), based on a set of themes which enable teachers to reflect collectively on secondary school as the final and essential stage of basic education. The first phase of the training had the theme "Subjects of secondary school and integral human education," and the second included an in-depth examination of the fields of knowledge, comprehending the collective re-writing of the school's political-pedagogical project. The peculiarity and effectiveness of this program lies in the centrality of school as privileged locus of education and in the teacher as an epistemic subject who creates and produces knowledge.

Keywords: secondary education; teacher training; analysis of teaching practice.

\section{Introdução}

O artigo insere-se no debate atual sobre o ensino médio brasileiro, tematizando a especificidade da docência nessa etapa da educação básica e suas demandas por uma formação continuada que considere os sujeitos da escola e os princípios das Diretrizes Curriculares Nacionais para o Ensino Médio (DCNEM). O escopo do texto é examinar o impacto de um processo formativo que alcançou 170.919 professores em todo o território nacional, conforme dados coletados no Sistema Integrado de Monitoramento, Execução e Controle do Ministério da Educação (Simec). De modo preciso, visa descrever e analisar a formação continuada para professores do ensino médio da rede pública estadual de Minas Gerais, desenvolvida pela equipe do Observatório de Juventude da Universidade Federal de Minas Gerais (UFMG), em parceria com a Secretaria de Educação Básica do Ministério da Educação (SEB/ MEC) e a Secretaria Estadual de Educação de Minas Gerais (SEE/MG).

A centralidade da escola como locus privilegiado para a formação e reflexão e do professor como sujeito epistêmico que elabora e produz conhecimento demonstra a capilaridade desse processo formativo. Destaca-se a prevalência da formação continuada estruturada como trabalho coletivo, uma dimensão pouco explorada nas ações de formação continuada e que foi privilegiada nessa proposta. 
O Pacto Nacional pelo Fortalecimento do Ensino Médio (PNEM), instituído pela Portaria MEC $n^{\circ} 1.140 / 2013$, define as diretrizes gerais para a implementação da proposta em território nacional, abarcando as 27 unidades da Federação e 495.600 docentes dessa etapa do ensino, que lecionavam em 20 mil escolas públicas, conforme dados do Censo Escolar de 2012. O recorte que trazemos para este artigo decorre da ação realizada no estado de Minas Gerais e, mais especificamente, no conjunto de superintendências regionais de ensino vinculadas à UFMG.

Nesse sentido, a formação envolveu 778 escolas e 9.075 docentes, entre professores e coordenadores pedagógicos. Os dados coletados em instrumentos de avaliação, sistematizados e discutidos neste trabalho, assinalam a permeabilidade de uma formação continuada que, tendo o protagonismo docente na condução de seu processo formativo, tornou possível a esses sujeitos habitar a escola.

\section{$O$ contexto do ensino médio}

Até o final dos anos 1980, o ensino médio público foi marcado por uma dualidade: um ensino voltado para a formação das elites e outro para os filhos da classe trabalhadora. Enquanto o primeiro era um ensino propedêutico, uma formação que preparava o jovem para entrar na universidade, o ensino secundário profissionalizante significava o final da escolarização para os jovens pobres que conseguiam chegar a essa etapa e o ingresso aligeirado no mercado do trabalho.

A Lei de Diretrizes e Bases da Educação Nacional, de 1996, trouxe a "progressiva obrigatoriedade" do ensino médio, instituído como etapa final da educação básica. A Emenda Constitucional n 59/2009, alterou a Constituição Federal de 1988, art. 208, inciso I, no sentido de estabelecer que "a educação básica [será] obrigatória e gratuita dos 4 aos 17 anos de idade, assegurada inclusive sua oferta gratuita para todos os que a ela não tiveram acesso na idade própria" (Brasil, 2009). O ensino médio passou a ser um direito público subjetivo a partir de 2016, como prevê a Emenda, uma vez que este se inicia aos 15 anos, quando não há distorção idade-série.

Diante dessa nova realidade normativa-educacional, o Plano Nacional de Educação, Lei no 13.005/2014, estabeleceu como Meta 3: "Universalizar, até 2016, o atendimento escolar para toda a população de 15 a 17 anos e elevar, até o final do período de vigência deste PNE (2024), a taxa líquida de matrículas no ensino médio para 85\% (oitenta e cinco por cento)" (Brasil, 2014).

Não obstante a meta, em 2015 a escolarização bruta era de 83,3\% e a escolarização líquida, 56,9\% para os jovens nessa faixa etária. Dos jovens não matriculados, $16 \%$ estavam fora da escola e $27,1 \%$, retidos no ensino fundamental. Direcionando nosso olhar para os jovens de 18-24 anos, em 2013, constatamos que $31 \%$ não haviam concluído o ensino médio e não estavam estudando.

O abandono escolar precoce, a distorção idade-série e as altas taxas de repetência contribuem para a manutenção de uma baixa taxa de anos de escolarização no Brasil. As taxas de insucesso (soma de abandono e reprovação) 
sugerem um certo desengajamento do aluno no decorrer da escolarização. Os maiores gargalos estão no terceiro e no sexto ano do ensino fundamental, com 13,3\% e 19,2\% de insucesso, respectivamente, chegando a 27,5\% no primeiro ano do ensino médio (Brasil. Inep, 2016).

Ao investigar o perfil do grupo com distorção idade-série, isto é, dos estudantes que frequentavam o ensino fundamental regular com idade de dois anos ou mais acima da adequada para a série/ano que cursavam, observa-se que as taxas de distorção são mais elevadas nas regiões Norte e Nordeste, entre estudantes da rede de ensino pública, homens, residentes em área rural e de cor preta ou parda. Analisando por níveis socioeconômicos, observa-se que o primeiro quinto dos estudantes mais pobres possuía taxa de distorção idade-série 3,3 vezes maior do que os alunos pertencentes aos $20 \%$ mais ricos. O atraso escolar, nesse período, afetava 54\% dos estudantes mais pobres.

Os dados apresentados demonstram que, especialmente na última década, a sociedade brasileira vivenciou um aumento na taxa de escolarização bruta e uma evolução na taxa média de anos de estudo, mas o aumento na porcentagem das matrículas não significou crescimento constante. No período 2011-2016, por exemplo, as matrículas se estabilizaram, com pequenas oscilações entre crescimento e queda. Importante notar que o crescimento das matrículas ocorreu entre jovens da zona rural, enquanto as quedas incidiram sobre a zona urbana.

Recorrendo a autores que analisam a relação entre jovens e escola, vislumbramos dois aspectos que merecem destaque nesse novo cenário da educação básica brasileira. O primeiro refere-se à qualidade do ensino. Pellegrino e Carrano (2003) falam de uma escolarização expandida no tempo e degradada na qualidade. Nas adjacências dessa expansão quantitativa da educação básica e crescente universalização do acesso, constitui-se um quadro de desigualdade sistêmica no que se refere à qualidade da experiência escolar para os jovens das camadas populares. Indagando pelas condições efetivas de permanência na escola, observa-se que o acesso dos jovens das camadas populares ao sistema de ensino vem acompanhado de práticas brandas ou dissimuladas de exclusão. Ao contrário da inequívoca reprovação, o processo de eliminação é diluído no tempo, fazendo com que a instituição escolar seja permanentemente habitada por excluídos potenciais (Bourdieu; Champagne, 1998).

Para Dubet (1994), esses novos alunos vivem uma situação paradoxal. São os grandes beneficiários da massificação do ensino e em suas famílias são a primeira geração a alcançar o ensino médio e a inscrever-se no projeto de mobilidade social, porém, suas capacidades de projetar um futuro profissional têm sido progressivamente menores e a escolarização não tem sido suficiente para evitar a exclusão social.

O segundo aspecto nos endereça aos sujeitos da escola, os jovens alunos, que adentram a escola e não o fazem somente na condição de estudantes. Suas demandas por uma escolarização de qualidade se articulam com as especificidades de quem experimenta a juventude como condição - tal como a sociedade constitui essa fase da vida, na qual se conjugam também as dimensões biológicas e etárias - e como situação, que se configura nos atravessamentos de classe, sexualidade, pertencimento étnico-racial, gênero, território, dentre outros. 
As DCNEM trazem uma reconceptualização do ensino médio com uma proposta de formação integral e a centralidade da pesquisa e o trabalho como princípios pedagógicos e educativos. Sobretudo, as DCNEM tomam como pressuposto a necessidade de estimular o envolvimento e a participação dos jovens no cotidiano das suas escolas e a importância de desvendar o sentido atribuído por eles à educação, indicando que a construção de uma política educacional para o ensino médio deve atentar para as demandas concretas da juventude.

Nesse sentido, a formação dos professores que atuam nessa etapa do ensino é condição primordial para o exercício da docência. O PNEM emerge nesse contexto como um programa de formação continuada que contempla os pressupostos norteadores da elaboração das diretrizes curriculares nacionais, marcando um novo ponto de inflexão na política educacional para o ensino médio.

\section{Ser professor no ensino médio: desafios e contradições}

Enquanto as décadas de 1990 e 2000, no Brasil, estiveram voltadas à universalização do ensino fundamental, o ensino médio era oportunizado de maneira residual. Com poucos avanços e muitos retrocessos, Costa, Oliveira e Medeiros (2016) argumentam que, historicamente, o ensino médio no Brasil vem constituindo-se em um campo de disputa e, paradoxalmente, não considerado prioritário nas políticas educacionais. Essa tensão incide diretamente sobre a condição de trabalho dos professores, ao viverem cotidianamente a falta de identidade e a ausência de políticas públicas educacionais voltadas para o atendimento das demandas estruturais dessa etapa da educação básica.

De acordo com o Censo Escolar da Educação Básica 1995 a 2015, a configuração do perfil dos professores do ensino médio é apresentada nos Gráficos 1 e 2.

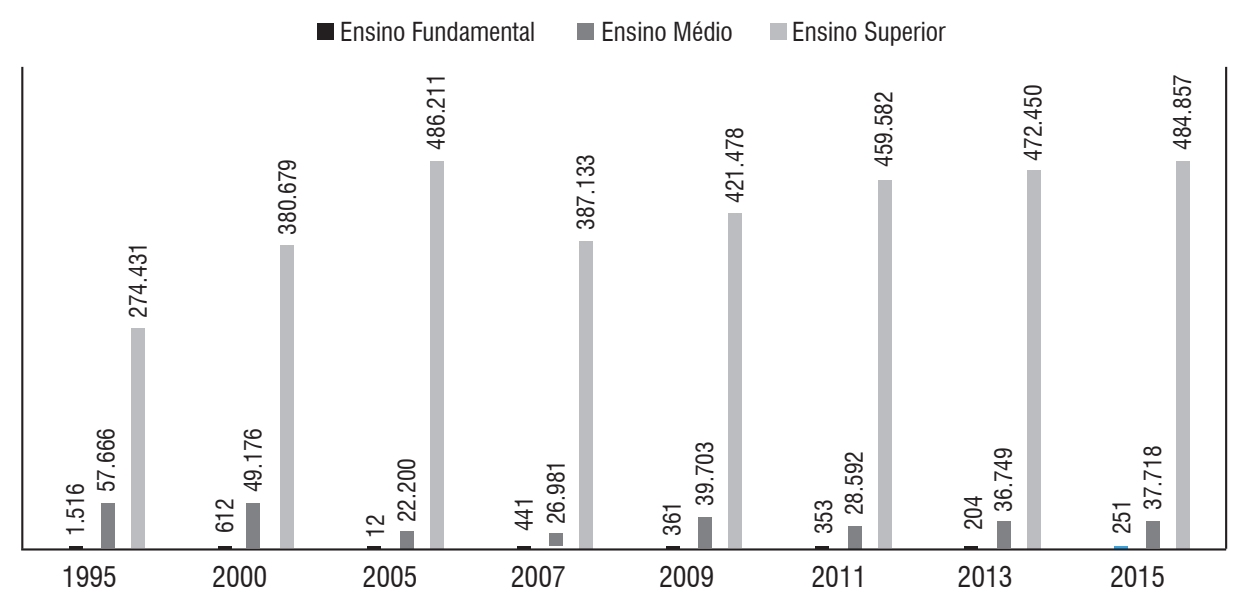

Gráfico 1 - Professores do ensino médio no Brasil segundo a escolaridade (1995-2015) 


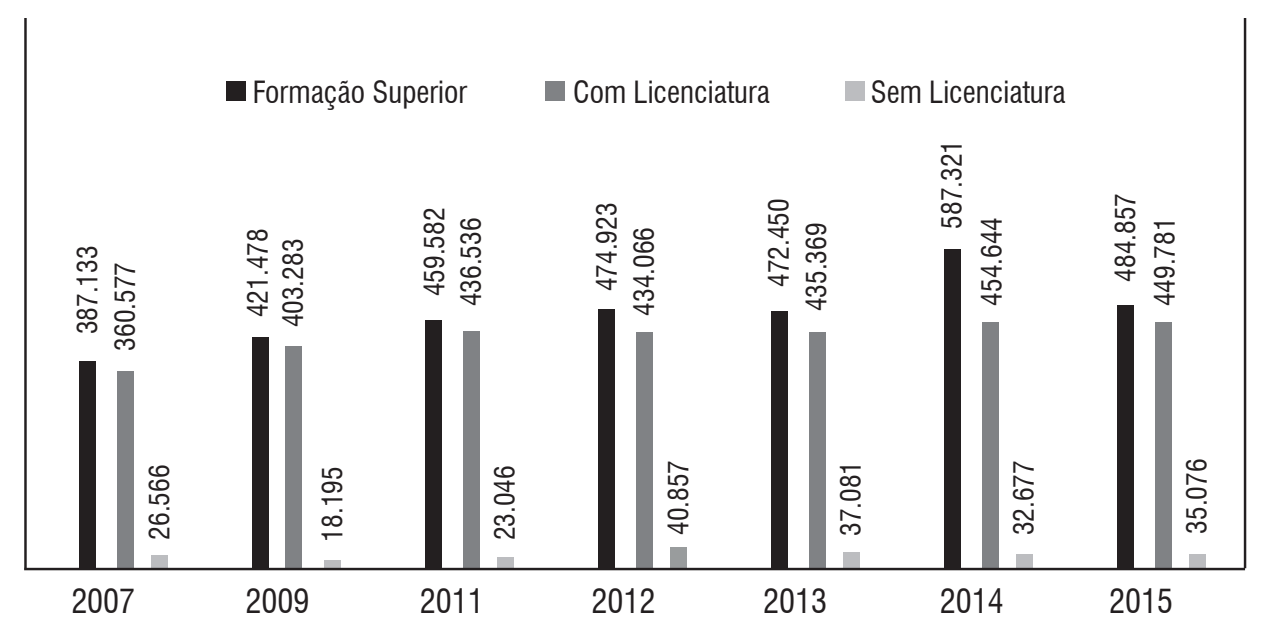

Gráfico 2 - Professores do ensino médio segundo a formação acadêmica (2007-2015)

Fonte: Brasil (2015a apud Costa; Oliveira; Medeiros, 2016, p. 91)

As informações do Gráfico 1 mostram que a formação em nível superior do professor do ensino médio teve um acréscimo de 10\% nos últimos 10 anos. A taxa de professores com licenciatura também se manteve elevada, mas ao considerarmos os números de professores do ensino médio, com nível superior, sem licenciatura (Gráfico 2), percebemos que essa porcentagem tem aumentado ligeiramente, ainda que com picos mais acentuados entre 2011 e 2013.

Costa, Oliveira e Medeiros (2016) chamam atenção a esse respeito: professores do ensino médio com licenciatura ou com complementação pedagógica representam um percentual de $87 \%$, enquanto 13\% lecionam sem estar habilitados para o exercício da docência. O número de docentes que não lecionam na disciplina de sua formação inicial constitui um dos desafios concernentes à formação do professor, sinalizada pela meta 15 do PNE. Essa meta prevê que todos os professores e professoras da educação básica devem possuir formação específica de nível superior, obtida em curso de licenciatura na área em que atuam até 2024. Entretanto, em 2015, segundo dados do PNE, apenas 53,8\% dos docentes possuíam formação superior compatível com a área de conhecimento em que atuavam como professores. Em Minas Gerais, esse percentual era $63,4 \%$.

O problema da atratividade da carreira é um dos fatores que mais bem pode ser associado à "falta" de professores para determinadas disciplinas no ensino médio. A questão é que não se pode falar apropriadamente em "falta" de professores, mas sim na procura de outro tipo de trabalho e renda pelos profissionais do magistério, uma vez que o baixo prestígio e a baixa remuneração fazem com que os professores exerçam uma espécie de "fuga de rota", direcionando-se para outro tipo de atividade laboral.

Para Kuenzer (2011), a política de formação inicial só faz sentido se conjugada a uma reestruturação da carreira docente, com uma política salarial que assegure dignidade aos professores e garantia de condições adequadas de trabalho, pois esses fatores, quando associados, incidem na qualidade da educação básica. 
Costa, Oliveira e Medeiros (2016) lembram ainda que a formação do professor do ensino médio deve, além desses parâmetros, articular "conhecimentos sobre o mundo do trabalho, conhecimentos científico-tecnológicos sobre a área a ser ensinada, conhecimentos pedagógicos e formação em pesquisa" (Kuenzer, 2011, p. 683). Todos esses campos a serem apreendidos pressupõem que a formação não se esgota no curso de licenciatura, exigindo uma articulação fina e equilibrada entre formação inicial e continuada do professor.

A expansão quantitativa da formação inicial de professores não pode ser dissociada da preocupação com a qualidade dessa expansão. O cumprimento da meta 15 pressupõe uma agenda articulada entre universidades, secretarias estaduais de educação e União para que a formação continuada se construa a partir de uma articulação mais orgânica com a formação inicial, aproximando o currículo das licenciaturas à realidade das escolas. O PNEM foi um programa atinente a essas questões. Ao tomar as instituições de ensino como espaço de reflexão, materializou uma perspectiva de formação centrada na escola e nas questões que tocam diretamente a prática pedagógica e a relação professor-aluno.

\section{O Pacto Nacional pelo Fortalecimento do Ensino Médio: estrutura de formação e o papel da universidade na formação continuada para o professor de educação básica}

A formação continuada de professores do ensino médio foi uma das duas ações estabelecidas pelo PNEM, que teve como finalidade iniciar um processo de rediscussão das práticas docentes à luz das diretrizes curriculares para a formação da juventude do País. Considerando o conjunto de mecanismos institucionais aprovados, as demandas por uma reformulação dessa etapa do ensino, a SEB/MEC apresentou uma proposta de formação que articulasse os esforços dos entes federados e das instituições públicas de ensino superior e, em consonância com os interesses da sociedade civil, chegasse aos professores do ensino médio das escolas públicas.

Estruturado para assegurar o aprofundamento e a atualização de conceitos fundamentais que norteiam o ensino médio, o curso foi desenvolvido em duas etapas de 100 horas cada. A primeira teve como eixo a temática "Sujeitos do ensino médio e formação humana integral", em conformidade com as DCNEM. As reflexões sobre os sujeitos da escola, em especial as juventudes, pautaram os encontros. Formação humana integral, currículo, integração curricular, gestão e avaliação foram os outros temas explorados. A segunda etapa apresentou como eixo a organização do trabalho pedagógico, com base nas áreas de conhecimento: ciências humanas, ciências da natureza, linguagens e matemática.

A perspectiva de uma formação que abarcasse o conjunto de professores do ensino médio e a heterogênea organização deste em cada estado motivou a SEB/ MEC a produzir materiais pedagógicos que norteassem as discussões nos grupos de estudos. Os cadernos temáticos funcionaram como âncoras que possibilitaram às secretarias estaduais e distrital de educação sustentarem o processo formativo. 
Quadro 1 - Cadernos temáticos do PNEM ${ }^{1}$

\begin{tabular}{|c|c|}
\hline Etapas & Título \\
\hline \multirow{6}{*}{ Etapa I } & Caderno I - Ensino médio e formação humana integral \\
\hline & Caderno II - O jovem como sujeito do ensino médio \\
\hline & $\begin{array}{c}\text { Caderno III - O currículo do ensino médio, seus sujeitos e os desafios } \\
\text { da formação humana integral }\end{array}$ \\
\hline & Caderno IV - Área de conhecimento e integração curricular \\
\hline & Caderno V - Organização e gestão democrática na escola \\
\hline & Caderno VI - Avaliação do ensino médio \\
\hline \multirow{5}{*}{ Etapa II } & Caderno I - Organização do trabalho pedagógico no ensino médio \\
\hline & Caderno II - Ciências humanas \\
\hline & Caderno III - Ciências da natureza \\
\hline & Caderno IV - Linguagens \\
\hline & Caderno V - Matemática \\
\hline
\end{tabular}

${ }^{1}$ Encontram-se disponíveis em: <http://observatoriodajuventude.ufmg.br/pacto-mg/materiais > ; <http://pactoensinomedio.mec.gov.br/index.php?option =com_content\&view = category\&id =13\&Itemid =117>

\section{A configuração do PNEM em Minas Gerais}

A adesão das secretarias estaduais de educação (Seducs) e das instituições de ensino superior (IES) à proposta de formação elaborada pela SEB/MEC transcorreu de maneira distinta. Iniciou-se com a mobilização do Conselho Nacional de Secretários de Educação (Consed), bem como das universidades, culminando na realização do I Seminário Nacional do PNEM, que reuniu representantes das IES, das Seducs e da SEB/MEC, em outubro de 2013.

Em dezembro do mesmo ano, a SEE/MG aderiu à parceria, estendendo o convite às IES públicas mineiras. Após uma série de arranjos internos, chegou-se a um desenho próprio e estruturado que direcionava a formação de professores em Minas Gerais. O desenho foi construído coletivamente por representantes da secretaria estadual e de oito universidades públicas federais e estaduais:

- Universidade Estadual de Minas Gerais

- Universidade Estadual de Montes Claros

- Universidade Federal de Itajubá

- Universidade Federal de Juiz de Fora

- Universidade Federal de Minas Gerais

- Universidade Federal de Uberlândia

- Universidade Federal de Viçosa

- Universidade Federal do Triângulo Mineiro

O Polo UFMG, que teve a Universidade Estadual de Minas Gerais (UEMG) como instituição de ensino associada, assumiu o processo formativo de professores vinculados a 12 superintendências regionais de ensino: Caratinga, Coronel Fabriciano, Curvelo, Governador Valadares, Guanhães, Manhuaçu, Metropolitanas A, B e C, Nova Era, Pará de Minas e Sete Lagoas 
O Quadro 2 sintetiza a proposta de organização que norteou o processo formativo realizado nas escolas. Ressalta-se, portanto, a autonomia que as Seducs e IES tiveram para estruturar as ações, respeitando e contemplando atividades em andamento, calendários letivos e outros aspectos que constituem as especificidades regionais e administrativas.

\section{A avaliação da formação: o que dizem os professores}

Em um sugestivo livro intitulado A vez e a voz dos professores, Sarmento (1994) reconstrói o sistema de crenças, valores, representações sociais e artefatos culturais no qual se tece o diálogo entre os professores e o sistema organizacional em que são filiados e mediante o qual se exprimem a divergência e o conflito entre as pessoas. Para isso, foi preciso dar voz aos professores. Assim, embora o lastro temporal entre o término da formação continuada coordenada pela UFMG no âmbito do PNEM seja ainda muito recente, buscamos recuperar a "voz" dos professores por meio de um questionário avaliativo em que pudéssemos entender e refletir acerca do alcance e dos desafios presentes no trabalho deles.

No final da formação, a equipe UFMG-UEMG elaborou um questionário avaliativo online e solicitou que todos os cursistas respondessem. Os respondentes foram 8.528 professores e coordenadores pedagógicos, de um total aproximado de 9 mil professores participantes das duas etapas do PNEM. Parte das questões que compuseram o questionário dispunham a seguinte escala de avaliação:

- Integral: para aqueles que participaram e desenvolveram 100\% das atividades propostas;

- Suficiente: para aqueles que cumpriram e participaram da maior parte das atividades propostas;

- Insuficiente: para aqueles que não cumpriram e não participaram da maior parte das atividades propostas;

- Não realizou as atividades: para aqueles que não cumpriram e não participaram das atividades propostas.

Os professores e coordenadores se mostraram bastante envolvidos durante todo o processo de formação. Uma das razões desse envolvimento pode ser atribuída ao fato de os professores utilizarem o horário de planejamento coletivo para realizar a formação. Essa garantia de uma carga horária destinada à formação foi um dos critérios de adesão ao PNEM que deveria ser cumprido pelas secretarias estaduais de educação. No que concerne à SEE/MG, esse horário é chamado Módulo II, correspondendo a um terço da carga horária da jornada de 24 horas destinada às atividades extraclasse para planejamento, atividades pedagógicas e de avaliação, sendo 4 horas cumpridas em local livre, à escolha do professor e 4 horas a serem cumpridas na própria escola ou em local definido pela direção.

A formação realizada no chão da escola tocou em um tema já conhecido dos estudiosos da formação docente: a cultura do individualismo muito presente nas escolas. De acordo com Hargreaves (1998, p. 209), a colaboração e a colegialidade são tidas como as maiores virtudes nos processos de mudanças educativas e de desenvolvimento profissional dos professores. A frequência dos cursistas nos encontros de formação reflete o interesse e, ao mesmo tempo, o desafio de realizar uma formação no interior da escola (Gráfico 3). Do total, 87\% (7.368) disseram ter participado integralmente dos encontros. 
Quadro 2 - Proposta de organização geral do programa de formação de professores do ensino médio (2013-2014)

\begin{tabular}{|c|c|c|}
\hline Mês & & Ação \\
\hline $\begin{array}{l}\text { Out./nov. } \\
2013\end{array}$ & \multicolumn{2}{|l|}{ Seminário nacional I } \\
\hline $\begin{array}{l}\text { Dez. } 2013 \\
\text { Jan./fev. } \\
2014\end{array}$ & \multicolumn{2}{|c|}{ Seminário estadual I - Formação de formadores } \\
\hline Fev./2014 & \multicolumn{2}{|c|}{$\begin{array}{l}\text { Formação de formadores ( } 1^{\mathrm{a}} \text { etapa) } \\
\text { - Professores formadores regionais } \\
\text { - Orientadores de estudo }\end{array}$} \\
\hline $\begin{array}{l}\text { Etapa I } \\
\text { Mar./jul. }\end{array}$ & \multicolumn{2}{|c|}{$\begin{array}{l}\text { Curso de formação } \\
\text { - Estudo dos seis campos temáticos: Cadernos } \\
\text { a) Atividades individuais: ch }=50 \text { horas } \\
\text { b) Atividades coletivas (na escola): ch }=45 \text { horas }+3 \text { horas de abertura } \\
\text { do seminário }+2 \text { horas do seminário de avaliação da } 1^{\text {a }} \text { etapa }=50 \text { horas } \\
\text { Total: } 100 \text { horas }\end{array}$} \\
\hline Mar./2014 & 2 encontros $\times 3 \mathrm{~h}$ & \multirow{7}{*}{$\begin{array}{l}\text { ATIVIDADES COLETIVAS (na escola) } \\
\text { - Primeiro encontro ( } 3 \text { horas) destinado } \\
\text { a abertura e orientações da primeira etapa } \\
\text { do curso: procedimentos metodológicos, } \\
\text { finalidades, uso de tecnologias). } \\
\text { - } 15 \text { encontros de } 3 \text { horas para serem } \\
\text { distribuídas nos seis campos temáticos } \\
\text { (textos elaborados para formação). } \\
\text { - } 2 \text { horas: avaliação } 1^{\text {a }} \text { etapa. } \\
\text { Total: } 50 \text { horas. }\end{array}$} \\
\hline Abr. & 4 encontros $\times 3 \mathrm{~h}$ & \\
\hline Maio & 5 encontros $\times 3 h$ & \\
\hline \multirow{2}{*}{ Maio } & $\begin{array}{l}\text { Seminário nacional II } \\
-2^{\mathrm{a}} \text { etapa }\end{array}$ & \\
\hline & $\begin{array}{l}\text { Seminário estadual II } \\
-2^{\mathrm{a}} \text { etapa }\end{array}$ & \\
\hline Jun. & 2 encontros $\times 3 \mathrm{~h}$ & \\
\hline Jul. & 2 encontros $\times 3 \mathrm{~h}$ & \\
\hline Jun./jul. & \multicolumn{2}{|c|}{$\begin{array}{l}\text { Formação de Formadores ( } 2^{\text {a }} \text { Etapa) } \\
\text { - Professores formadores regionais } \\
\text { - Orientadores de estudo }\end{array}$} \\
\hline $\begin{array}{l}\text { Etapa II } \\
\text { Ago./dez. }\end{array}$ & \multicolumn{2}{|c|}{$\begin{array}{l}\text { Curso de formação } \\
\text { - Estudo das DCNEM, áreas do conhecimento e reescrita do PPP } \\
\text { a) Atividades individuais: ch }=50 \text { horas } \\
\text { b) Atividades coletivas (na escola): } 50 \text { horas. } \\
\text { Total: } 100 \text { horas }\end{array}$} \\
\hline Ago. & 4 encontros $\times 3 \mathrm{~h}$ & \multirow{7}{*}{$\begin{array}{l}\text { ATIVIDADES COLETIVAS (na escola) } \\
\text { - Primeiro encontro ( } 3 \text { horas) destinado } \\
\text { à abertura e orientações da segunda etapa } \\
\text { do curso: procedimentos metodológicos, } \\
\text { finalidades, uso de tecnologias e articulação } \\
\text { com a reescrita do PPP. } \\
\text { - } 13 \text { encontros de } 3 \text { h ( } 39 \text { horas) para estudos } \\
\text { sobre as DCNEM, as áreas de conhecimento } \\
\text { e seus componentes curriculares (textos a } \\
\text { serem elaborados para essa etapa). } \\
\text { - Realização de dois seminários integradores na } \\
\text { escola para reescrita do PPP. } \\
\text { - } 1 \text { encontro de } 2 \text { horas destinado à realização de } \\
\text { seminário final de avaliação do curso na escola } \\
\text { Total: } 50 \text { horas. }\end{array}$} \\
\hline Set. & 4 encontros $\times 3 \mathrm{~h}$ & \\
\hline \multirow[t]{2}{*}{ Out. } & $\begin{array}{l}\text { Seminário nacional III } \\
\text { - Avalilação geral do curso } \\
\text { de formação } \\
\text { Seminário estadual III } \\
\text { - Avalilação geral do curso } \\
\text { de formação }\end{array}$ & \\
\hline & 5 encontros $\times 3 \mathrm{~h}$ & \\
\hline \multirow[t]{2}{*}{ Nov. } & $\begin{array}{l}\text { Seminário nacional de } \\
\text { articulação entre formação } \\
\text { inicial e continuada: } \\
\text { discussão sobre as } \\
\text { licenciaturas }\end{array}$ & \\
\hline & 4 encontros de 3 horas & \\
\hline Dez. & $\begin{array}{l}2 \text { encontros: } 1 \text { encontro }=3 \mathrm{~h} \\
1 \text { encontro de } 2 \text { h: } \\
\text { Seminário final de avaliação } \\
\text { da formação continuada } \\
\text { na escola: relatos } \\
\text { de experiência e sugestões }\end{array}$ & \\
\hline $\begin{array}{l}\text { Carga } \\
\text { horária } \\
\text { total }\end{array}$ & $\begin{array}{l}1^{\mathrm{a}} \text { etapa: } 100 \text { horas } \\
2^{\mathrm{a}} \text { etapa: } 100 \text { horas }\end{array}$ & 200 horas \\
\hline
\end{tabular}

Fonte: Brasil. MEC, 2013c, p. 15. 


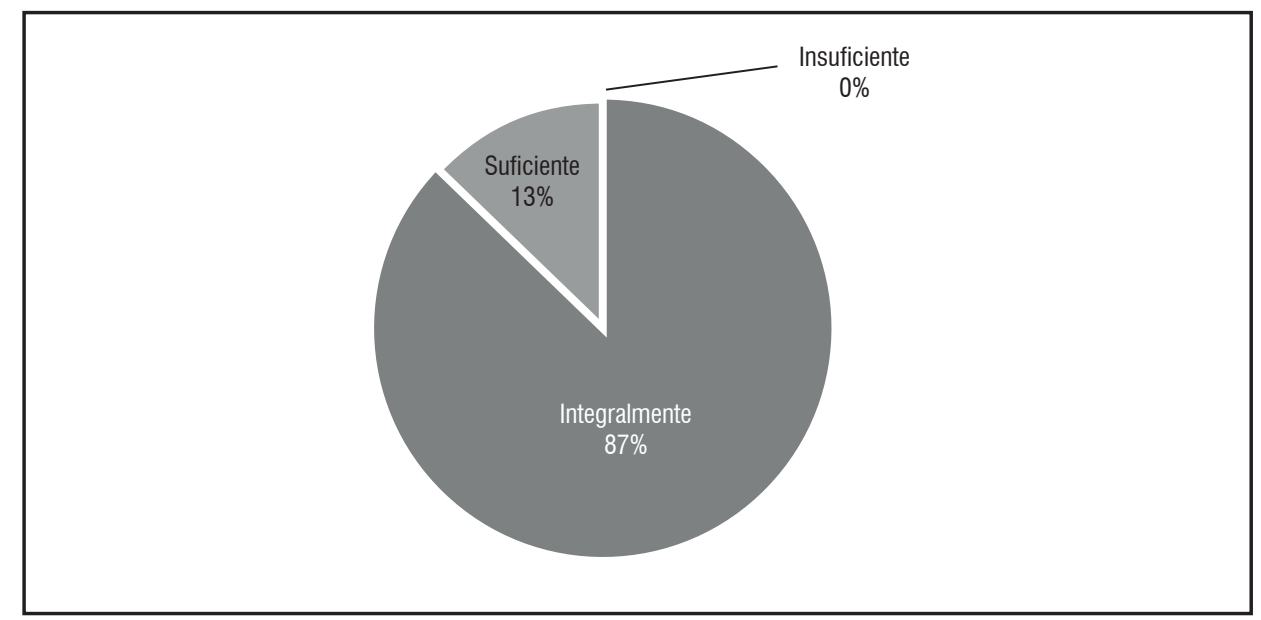

Gráfico 3 - Participação nos encontros presenciais de formação

Fonte: Dados relatório PNEM (UFMG, 2016)

O Gráfico 4 permite afirmar que as atividades indicadas para um horário diferente da formação presencial também foram avaliadas positivamente pelos cursistas. Ou seja, os professores e coordenadores pedagógicos utilizaram outros momentos para desenvolver as atividades propostas e estudar os conteúdos sugeridos pelos cadernos temáticos.

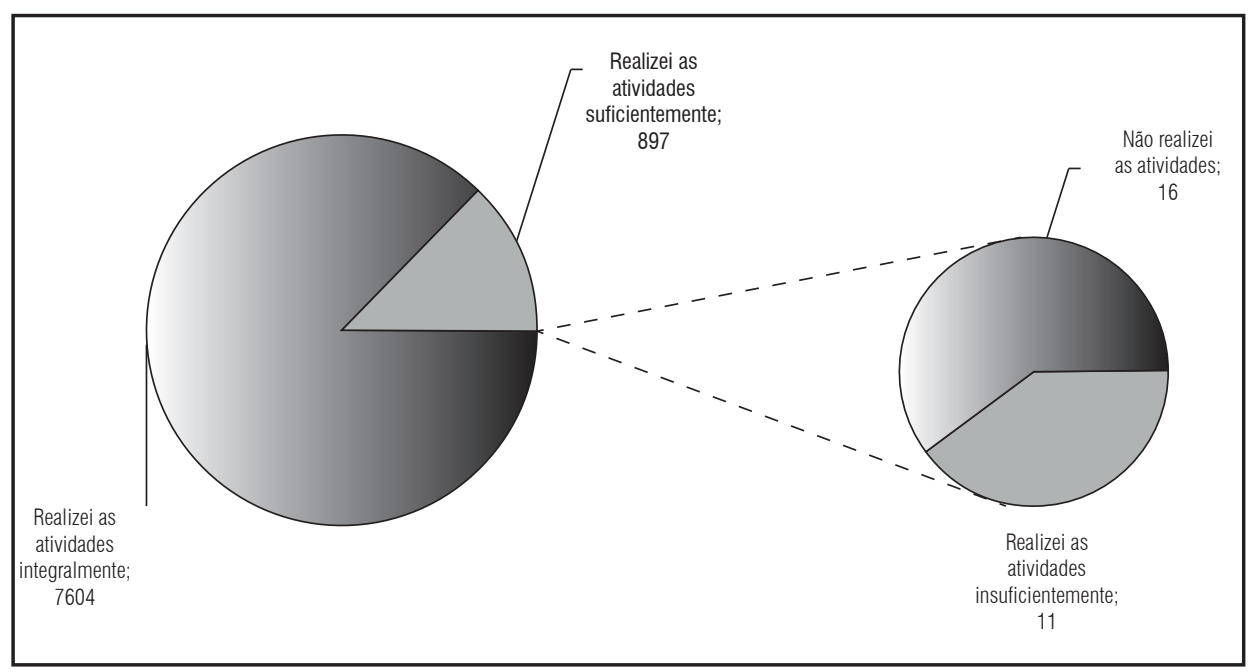

\section{Gráfico 4 - Realização de atividades individuais}

Fonte: Dados relatório PNEM (UFMG, 2016).

A construção de novos conceitos, procedimentos e atitudes foi um dos objetivos da formação. Sobre isso, 7.115 cursistas julgaram que aproveitaram a formação integralmente e 1.395 suficientemente. Apenas um cursista afirmou ter aproveitado insuficientemente (Gráfico 5). 


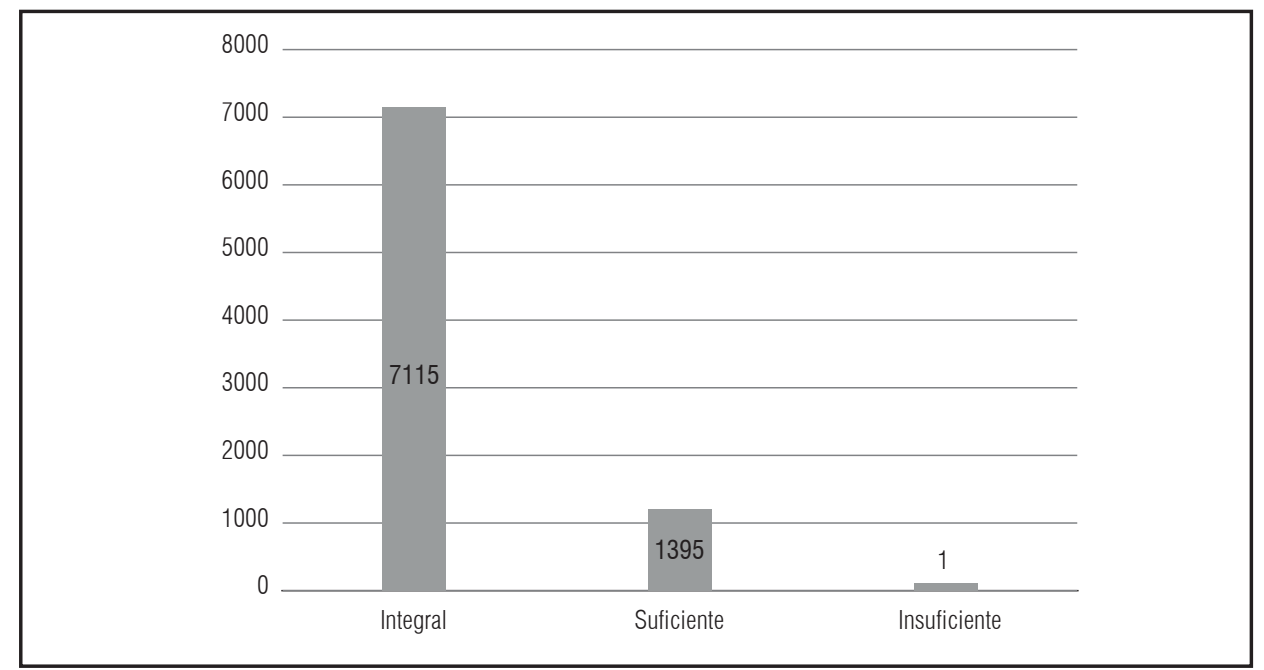

Gráfico 5 - Aproveitamento do curso

Fonte: Dados relatório PNEM (UFMG, 2016).

Os fatores que contribuíram para a participação e a permanência na formação (Gráfico 6) foram: a aplicabilidade na prática profissional (23\%), o trabalho coletivo na escola (21\%) e o relacionamento com o grupo na formação (21\%). Em relação a esse dados, é possível supor que a eficácia da formação continuada com as características do PNEM situa-se na sua materialidade, porque os desafios vivenciados pelos professores no cotidiano pedagógico encontraram eco nos materiais estudados (Cadernos) e, também, nas discussões propiciadas pelo trabalho coletivo.

O relacionamento com os colegas também foi evidenciado como algo positivo. Não é por acaso que, para Hargreaves (1998, p.211), a colaboração e a colegialidade formam plataformas significativas de políticas que procuram tanto reestruturar as escolas a partir do exterior, quanto melhorá-las a partir do interior. Tal dinâmica instala uma nova lógica no ambiente escolar, fazendo com que os professores percebam que podem se beneficiar com as experiências uns dos outros e que o processo de formação não se esgota em cursos ou programas de curta duração.

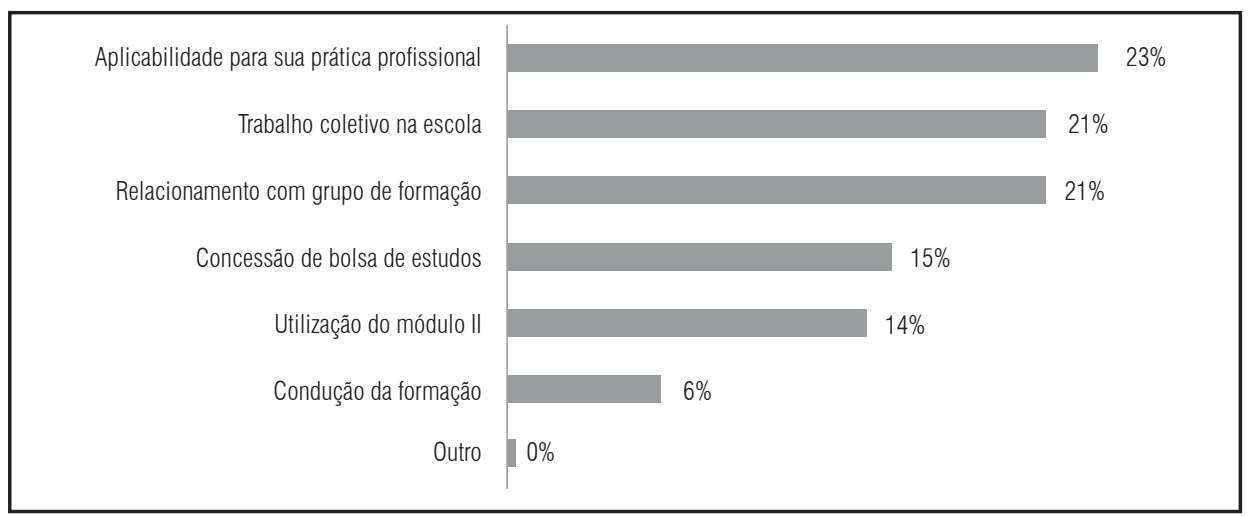

Gráfico 6 - Fatores que contribuíram para a participação e a permanência na formação 
Se, por um lado, o trabalho colaborativo figura como um fator de aderência aos projetos de formação continuada, por outro, o trabalho coletivo aparece, para $27 \%$ dos cursistas, como uma dificuldade enfrentada durante a formação, seguida da dificuldade de aplicar os conhecimentos na prática profissional (Gráfico 7). Neste aspecto, Hargreaves (1998, p. 219) lembra que as culturas de colaboração são muitas e tendem a ser espontâneas, voluntárias, orientadas para o desenvolvimento, alargadas no tempo e no espaço. Quando a cultura colaborativa supõe uma colegialidade artificial, os tempos e espaços passam a ser regulados administrativamente, as situações experimentadas podem soar compulsórias, sempre orientadas para a implementação, fixas no tempo e no espaço, além de previsíveis.

As dificuldades da formação relacionadas ao trabalho coletivo demonstram ainda o quanto as dinâmicas pedagógicas em nossas escolas estão presumidas por rotinas individualistas, muitas vezes competitivas entre os pares, orientadas quase sempre por uma lógica de centralização na figura do gestor. Talvez, como lembra Hargreaves (1998, p. 235), é passada a hora de conceder às comunidades docentes a flexibilidade necessária para trabalharem em comum no desenvolvimento de seus próprios programas. Para o autor, trata-se de uma questão de devolução séria e ampla de poder às nossas escolas e aos nossos professores, sujeitos que vivenciam e experimentam os desafios postos pela rotina pedagógica.

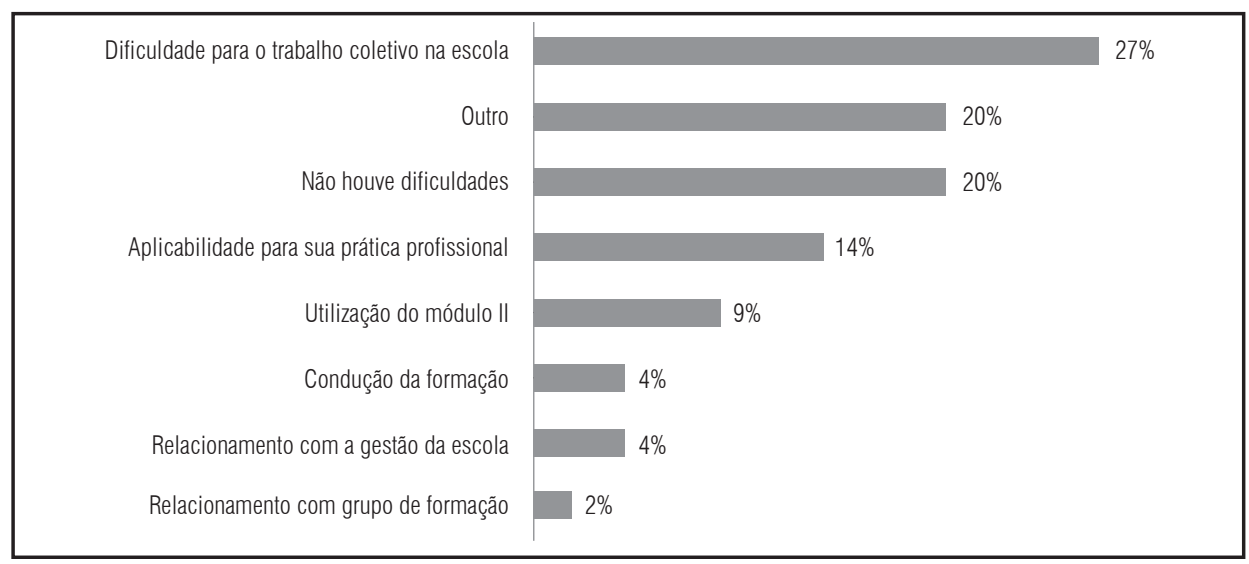

Gráfico 7 - Fatores que dificultaram a participação e a permanência na formação

Fonte: Dados relatório PNEM (UFMG, 2016).

A dificuldade em realizar o trabalho coletivo pode evidenciar a precariedade da condição docente no que se refere ao tempo disponível para dedicar-se à formação continuada. Nesse aspecto, o Censo Escolar de 2016 traz uma boa radiografia da condição docente nas escolas, mostrando que o Estado brasileiro (nos níveis municipal, estadual e federal) é o grande empregador dos professores, uma vez que 75,6 \% dos docentes trabalham exclusivamente na rede pública de ensino. O Censo ainda mostra que, dos 519.600 professores que atuam no ensino médio, 58,2\% 
atuam em uma única escola. Destes, um contingente expressivo atua em outras redes (municipal e/ou particular) ou dobram de turno na mesma escola para driblar o baixo salário que recebem com apenas um cargo.

\section{Considerações finais}

Paralelamente às ações governamentais que levaram à descontinuidade do PNEM, em setembro de 2016, tivemos a aprovação de uma controversa reforma do ensino médio. A mobilização dos estudantes, as ocupações de escolas, as manifestações das entidades educacionais e movimentos sociais, asseveram que o ensino médio é a etapa mais problemática da escolarização, no que tange à garantia do direito à educação básica. A aprovação pela Medida Provisória nº 746/2016 é, por si só, um indício de que não chegamos a produzir consensos sobre a finalidade do ensino médio e, portanto, sobre o destino que queremos para todos os jovens. Os desafios para a universalização dessa etapa da educação básica estão enraizados numa histórica desigualdade social que permeia a nossa sociedade.

O PNEM apresentou-se como uma perspectiva de formação continuada que buscava o reconhecimento das contradições acerca dos sentidos da escolarização, uma vez que elas estão impressas na prática pedagógica dos professores, e quaisquer mudanças requerem o empenho de cada professor, amparado por seus pares. Mesmo que tenha sido uma experiência limitada no tempo, os relatos das universidades e a avaliação do programa externada pelos professores em seus polos de formação confirmaram a assertividade dessa proposta e evidenciam que a descontinuidade do PNEM constitui um equívoco histórico para as políticas de formação inicial e continuada de professores no país, especialmente do ensino médio (Silva; Colontonio, 2015).

Embora este artigo não esgote a discussão sobre o impacto do processo formativo na prática docente, os dados coletados nesta experiência do PNEM revelam a satisfação do professor do ensino médio diante de uma política voltada à sua formação. Sujeito de uma etapa controversa, como assinalamos, o professor do ensino médio pôde recobrar, por meio do PNEM, o interesse pelas diferentes áreas em que atua e por saber que sua formação não prescinde de sua experiência. Tal como preconizam as diretrizes, o PNEM anunciava a exequibilidade de novos desenhos curriculares (os estudos dos conteúdos disciplinares eram apresentados por áreas de conhecimento). No decorrerda formação, privilegiou-se o professor como o sujeito e agente, incorporando a escola como espaço significativo das práticas ao longo de todo o processo, como trajeto educativo progressivo para o desenvolvimento de capacidades para a prática docente em situações e contextos reais.

Outra dimensão importante a ser destacada diz respeito à própria concepção do PNEM de não deslegitimar a prática docente, na medida em que procurou entender que a convergência das práticas pedagógicas empreendidas por esses sujeitos com a formação continuada inspira sempre práticas renovadas e não discursos pedagógicos muitas vezes teoréticos, alheios à realidade escolar dos sujeitos envolvidos 
no processo educativo.

O biênio marcado pelo PNEM (2014-2015) deixou alguns apontamentos sobre o lugar da formação continuada na vida do professor que merecem ser refletidos mais detidamente em futuras propostas:

1) a valorização da prática como fonte de experiência e capacitação profissional;

2) a importância das trocas situadas entre os sujeitos (no PNEM, a discussão iniciava-se com a leitura dos cadernos, mas estes eram mediados pela ideia do texto e contexto ressignificado pelo professor);

3) o papel do professor como construtor, intérprete e mediador da experiência;

4) a diversidade das situações postas pelos cadernos e sua complexidade, assim como suas dimensões implícitas com a prática pedagógica.

Esses fatores, agregados, foram capazes de tirar o professor do ensino médio de uma política de esquecimento, restabelecendo a importância do seu ofício na formação humana integral. Ao configurar o papel da docência nessa etapa da educação básica, diante de tantos desafios e contradições, torna-se evidente a potência de uma política de formação continuada articulada à formação inicial passível de conferir a vez e a voz aos professores do ensino médio.

\section{Referências bibliográficas}

ALVES, T.; REZENDE PINTO, J. M. Remuneração e características do trabalho docente no Brasil: um aporte. Cadernos de Pesquisa, São Paulo, v. 41, n. 143, p. 606-639, maio/ago. 2011. Disponível em: < http://www.scielo.br/pdf/cp/ v41n143/a14v41n143.pdf>.

BOURDIEU, P.; CHAMPAGNE, P. Os excluídos do interior. In: BOURDIEU, Pierre. Escritos de educação. Organizado por Maria Alice Nogueira e Afrânio Catani. Petrópolis, RJ: Vozes, 1998. p. 217-227.

BRASIL. Constituição (1988). Constituição da República Federativa do Brasil. Brasília: Câmara dos Deputados, 2016.

BRASIL. Emenda Constitucional n 59, de 11 de novembro de 2009. Acrescenta $\S 3^{\circ}$ ao art. 76 do Ato das Disposições Constitucionais Transitórias para reduzir, anualmente, a partir do exercício de 2009, o percentual da Desvinculação das Receitas da União incidente sobre os recursos destinados à manutenção e desenvolvimento do ensino de que trata o art. 212 da Constituição Federal, dá nova redação aos incisos I e VII do art. 208, de forma a prever a obrigatoriedade do ensino de quatro a dezessete anos e ampliar a abrangência dos programas suplementares para todas as etapas da educação básica, e dá nova redação ao $\S 4^{\circ}$ do art. 211 e ao $\S 3^{\circ}$ do art. 212 e ao caput do art. 214, com a inserção neste dispositivo de inciso VI. Diário Oficial da União, Brasília, DF, 12 nov. 2009. Seção 1, p. 8.

BRASIL. Lei no 9.394, de 20 de dezembro de 1996. Estabelece as Diretrizes 
e Bases da Educação Nacional. Diário Oficial da União, Brasília, DF, 23 dez. 1996. Seção 1, p. 27833.

BRASIL. Lei no 13.005, de 25 de junho de 2014. Aprova o Plano Nacional de Educação - PNE e dá outras providências. Diário Oficial da União, Brasília, DF, 26 jun. 2014. Seção 1, ed. extra, p. 1.

BRASIL. Medida provisória no 746, de 23 de setembro de 2016 [sumário executivo]. Ementa: Institui a Política de Fomento à Implementação de Escolas de Ensino Médio em Tempo Integral, altera a Lei no 9.394, de 20 de dezembro de 1996 [...] e a Lei no 11.494, de 20 de junho de 2007 [...]. Disponível em: <http://legis.senado.leg.br/comissoes/comissao;jsessionid=7BC357DB5AD502D1 616A79C11679219F?0\&codcol $=2065>$.

BRASIL. Conselho Nacional de Educação (CNE). Câmara de Educação Básica (CEB). Parecer $n^{\circ}$ 5, de 4 de maio de 2011. Diretrizes Curriculares Nacionais para o ensino médio. Disponível em: <http://pactoensinomedio.mec.gov.br/images/pdf/ pceb005_11.pdf>. Acesso em: 4 jun. 2016.

BRASIL. Conselho Nacional de Educação (CNE). Câmara de Educação Básica (CEB). Resolução no 2, de 30 de janeiro de 2012. Define Diretrizes Curriculares Nacionais para o ensino médio. Disponível em <http://pactoensinomedio.mec.gov. br/images/pdf/resolucao_ceb_002_30012012.pdf> Acesso em: 4 jun. 2016.

BRASIL. Instituto Nacional de Estudos e Pesquisas Educacionais Anísio Teixeira (Inep). Microdados: Censo da Educação Básica 2013. 2014. Disponível em: <http://portal.inep.gov.br/basica-censo>. Acesso em: 5 jun. 2016.

BRASIL. Ministério da Educação (MEC). PNE em movimento: situação das metas dos planos. 2013a. Disponível em: <http://simec.mec.gov.br/pde/graficopne. php>. Acesso em: 6 jun. 2016.

BRASIL. Ministério da Educação (MEC). Portaria n 1.140, de 22 de novembro de 2013. Institui o Pacto Nacional pelo Fortalecimento do Ensino Médio e define suas diretrizes gerais, forma, condições e critérios para a concessão de bolsas de estudo e pesquisa no âmbito do ensino médio público, nas redes estaduais e distrital de educação. Diário Oficial da União, Brasília, DF, 9 dez. 2013b. Seção 1, p. 24. Disponível em: < http://www.educadores.diaadia.pr.gov.br/arquivos/File/ pacto_nacional_em/portaria1140.pdf>. Acesso em: 4 jun. 2016.

BRASIL. Ministério da Educação (MEC). Secretaria de Educação Básica (SEB). Pacto Nacional pelo Ensino Médio: formação de professores do ensino médio: documento orientador preliminar. Brasília: MEC/SEB, 2013c. Disponível em: $<$ http://www.dpe.ufv.br/wp-content/uploads/Documento-Orientador.pdf > .

COSTA, G. L. M.; OLIVEIRA, C. S.; MEDEIROS, G. A formação do professor no ensino médio no Brasil e o Plano Nacional de Educação. Poiésis, Tubarão, SC, v. 10, n. 17, p. 85-101, jan./jun. 2016. Disponível em: < http://www. 
portaldeperiodicos.unisul.br/index.php/Poiesis/article/view/3891/2712>.

DUBET, F. Sociologie de l'expérience. Paris: Seuil, 1994.

HARGREAVES, A. Os professores em tempos de mudanças: o trabalho e a cultura dos professores na idade pós-moderna. Lisboa: McGraw-Hill de Portugal, 1998.

KRAWCZYK. N. O ensino médio no Brasil. São Paulo: Ação Educativa, 2009. (Série Em Questão, n. 6).

KUENZER, A. Z. A formação de professores para o ensino médio: velhos problemas, novos desafios. Educação \& Sociedade, Campinas, v. 32, n. 116, p. 667-688, jul./set. 2011. Disponível em: < http://www.scielo.br/pdf/es/v32n116/ a04v32n116.pdf>.

MAIA, C. L.; CORREA, L. M. Ver, ouvir e registrar: compondo um mosaico das juventudes brasileiras. In: CORREA, L. M.; ALVES, M. Z.; MAIA, C. L. (Org.). Cadernos temáticos: juventude brasileira e ensino médio. Belo Horizonte: Ed. da UFMG, 2014

PELLEGRINO, M.; CARRANO, P. Jovens e escola: compartilhando territórios e o sentido de presença. In: A ESCOLA e o mundo juvenil: experiências e reflexões. São Paulo: Ação Educativa, 2003. (Série Em Questão, n. 1).

OBSERVATÓRIO DO PNE. Meta 3: ensino médio. 2013. Disponível em: $<$ http://www.observatoriodopne.org.br/metas-pne/3-ensino-medio/ indicadores\# porcentagem-de-jovens-de-15-a-17-anos-matriculados-no-ensinomedio >. Acesso em: 5 jun. 2016.

RELATÓRIO do desenvolvimento humano 2015. Nova York: Programa das Nações Unidas para o Desenvolvimento, 2015.

SARMENTO, M. J. A vez e a voz dos professores: contributo para o estudo da cultura organizacional da escola primária. Porto: Porto Editora, 1994.

SILVA, M. R.; COLONTONIO, E. (Org.). Formação de professores do ensino médio: cadernos de resumos [do III Seminário do Pacto Nacional pelo Fortalecimento do Ensino Médio, Curitiba, 4 e 5 de maio de 2016]. Disponível em: http://www. observatoriodoensinomedio.ufpr.br/wp-content/uploads/2014/03/MEC-ResumosWEB.pdf

UNIVERSIDADE FEDERAL DE MINAS GERAIS. Relatório do Projeto de Formação Continuada: Pacto Nacional pelo Fortalecimento do Ensino Médio. Belo Horizonte, MG, 2016.

Licinia Maria Correa, doutora em Educação Escolar e mestre em Psicologia 
Social, é professora de Sociologia da Educação, no Departamento de Ciências Aplicadas à Educação, da Faculdade de Educação da Universidade Federal de Minas Gerais (FaE\UFMG), e integrante do Programa Observatório da Juventude da UFMG. liciniacorrea1@gmail.com

Maria Amália de Almeida Cunha, doutora em Educação pela Universidade Estadual de Campinas (Unicamp), com doutorado sanduíche em Sociologia pela Université Paris X Nanterre, é professora associada na Universidade Federal de Minas Gerais (UFMG) e pesquisadora do Observatório Sociológico Família-Escola (Osfe) do Núcleo de Pesquisa em Desigualdades Escolares (Nupede).

amaliacunha@hotmail.com

Teodoro Zanardi, doutor em Educação (Currículo) pela Pontifícia Universidade de São Paulo (PUC-SP) e pós-doutor em Educação pela Universidade de Colônia (Alemanha) com bolsa da Capes, é professor adjunto IV do Programa de Pósgraduação em Educação da PUC-MG e consultor na área de desenvolvimento curricular. Atua como comentarista semanal da Rádio CBN-BH, no quadro "Escola da Vida".

teozanardi@gmail.com

Liliane Oliveira Palhares da Silva, mestre em Educação Tecnológica pelo Centro de Educação Tecnológica de Minas Gerais (Cefet-MG), é professora do $1^{\circ}$ ciclo do ensino fundamental na Prefeitura de Belo Horizonte e atuou como supervisora do PNEM coordenado pela UFMG.

lili_palhares@hotmail.com 